\title{
Application of the Ozonation Pre-treatment for Biodegradation of Aqueous Solutions of Methyltert-Butyl Ether
}

\author{
${ }^{1}$ M. Sadeghi, ${ }^{2}$ A. Mesdaghinia, ${ }^{3}$ A. Badkoubi, ${ }^{4}$ R. Nabizadeh and ${ }^{1}$ A. Khavanin \\ ${ }^{1}$ Department of Occupational and Environmental Health, School of Medical Sciences, \\ Tarbiat Modarres University, Tehran, Iran \\ ${ }^{2}$ Center for Environmental Research, Tehran University of Medical Sciences, Tehran, Iran \\ ${ }^{3}$ Department of Environmental Engineering, School of Engineering, \\ Tarbiat Modarres University, Tehran, Iran \\ ${ }^{4}$ Department of Environmental Health Engineering, School of Public Health, \\ Tehran University of Medical Sciences, Tehran, Iran
}

\begin{abstract}
The effectiveness of ozone treatment for improving the biodegradability of recalcitrant pollutants has been proved by investigating the ozonation reaction of Methyl tert-butyl ether (MTBE) a bioresistant gasoline oxygenate. Laboratory scale experiments have been carried out, at room temperature, by bubbling, for $120 \mathrm{~min}$, ozonated air $\left(3.4 \mathrm{ppm} \mathrm{min}{ }^{-1}\right)$ into 3 liter of an alkaline $(\mathrm{pH}=11.5)$ aqueous solution $\left(100 \mathrm{mg} \mathrm{L}^{-1}\right)$ of MTBE. The experimental results indicated that during the ozonation, complete MTBE degradation occurs in $100 \mathrm{~min}$ and after this time, ozone consumption goes on very slowly. At the end of the ozonation, after $100 \mathrm{~min}$, the initial value of COD $\left(256 \mathrm{mg} \mathrm{O}_{2} \mathrm{~L}^{-1}\right.$ ) is 98 and correspond to a relative removal of about 62\%.As for MTBE solution biodegradability expressed as (BOD5)/(COD) ratio, during the first $90 \mathrm{~min}$ its value regularly increases from lowest (0.01) up to a maximum of 0.68 that corresponds to an ozone consumption of $1.25 \mathrm{mg}$ per each mg of COD initially present in the solution.The experimental results for determining the rate of MTBE removal due to stripping showed that about 14\% of MTBE strips out after an hour of sparging with oxygen gas. The fraction of MTBE oxidized and/or striped increases to about $28 \%$ (in $\mathrm{pH}=7$ ) and $70 \%$ (in $\mathrm{pH}=11.5$ ) with ozonation over the same time period.
\end{abstract}

Key words: Methyltert-Butyl Ether (MTBE), Ozonation, Pre-treatment, Biodegradability

\section{INTRODUCTION}

Biodegradability and toxicity of organic substances are significant factors for determining their behavior in a natural environmental and in the biological treatment of wastewater with respect to general organic substances that are relatively readily biodegraded, their degrees of biodegradability have been studied by many researchers [1]. However, more studies are required on substances that are very hard to biodegrade, specially Ether-bonded compounds,i.e. Metyl tert-Butyl Ether (MTBE) [2]. MTBE is commonly added to gasoline and has been utilized for the past tow decades [3]. The environmental fate of MTBE has become a subject of renewed interest due to the large quantities of this compound that are now being used to oxygenate gasoline [4].

MTBE is emitted by different sources into the aquatic environment. Leakage from underground storage tanks (LUSTs), Recreational wtercraft on lakes and effluents represent possible point sources by releases of MTBE into the environment $[5,6]$. Its presence in effluents has in fact been reported by the chemical industry [5]. The occurrence of MTBE in the hydrological cycle and its impact as a no point source contaminant has been investigated in several studies $[7,8]$.
Biological treatment of wastewater, groundwater and aqueous hazardous waste is often the most economical alternative when compared with other treatment options. The ability of a compound to undergo biological degradation is dependent on a variety of factors, such as concentration, chemical structure, substituents of the target compound, $\mathrm{pH}$ and the presence of inhibitory compounds. Although many organic molecules are readily degraded, many other synthetic and naturally occurring organic molecules for example; MTBE, are biorecalcitrant [9-11].

A rather innovative approach is provided by the so called "integrated-processes" where the effectiveness of combining biological and physico-chemical treatments is specifically designed to be synergetic rather than additive [11].

Several chemical processes, which use oxidizing agents such as, ozone, hydrogen peroxide, etc. have been carried out to mineralize many synthetic organic chemicals. However, costs associated with chemical oxidation alone can often be prohibitive for wastewater treatment. A potentially viable solution is the integration of chemical and biological treatment processes as an economical in wastewater. The chemical process would be used as a pre-treatment in order to increase the biodegradability of the wastewater. 
In these combined processes, if we want to determine the variation of biodegradability as a function of the chemical reaction conditions (time of pre-treatment, concentration of the oxidizing agent, temperature, etc.), a biodegradability test is required. Methods for measuring biodegradability in these systems have been proposed by a number of authors. BOD and BOD/COD or BOD/TOC are commonly used [12-15]. Other biodegradability measures including substrate destruction, oxygen uptake, $\mathrm{EC}_{50}$ toxicity measurements, cell growth counts and intracellular ATP levels also have been used [16].

Within the group of chemical oxidation processes, ozonation is one of the methods that gives better results in the oxidation of refractory contaminants $[14,17,18]$.

Refractory or recalcitrant compounds are those which resist aerobic microbial wastewater treatment under conductive environmental conditions. Compounds susceptible to ozonolysis are those containing $\mathrm{C}=\mathrm{C}$ double bonds, specific functional groups (e.g. $\mathrm{OH}, \mathrm{CH}_{3}$, $\left.\mathrm{OCH}_{3}\right)$ and atoms carrying a negative charge $(\mathrm{N}, \mathrm{P}, \mathrm{O}$, $\mathrm{S}$ and nucleophilic carbons) [15] which their ozonation in water usually produces oxygenated organic products and low molecular weight acids that are more biodegradable [13, 14, 19-21].

There are only very few works in literature [19, 22, 23] that report results of integrated chemical and biological oxidation of wastewaters, showing the effect of the chemical pre-treatment on the performance of the biological reactor. According to that, the effect of ozonation on the biodegradability of aqueous solutions of MTBE has been studied in this work. BOD/COD ratio and $\mathrm{COD}$ removal has been chosen as biodegradability indicator.

\section{MATERIALS AND METHODS}

Ozone was generated from oxygen gas by a OZN5R model ozonator . Reagent grade MTBE (MW=88.15, $>99.9 \%$ ) supplied by MERCK and deionized water (< 5 $\mu \Omega \mathrm{cm}^{-1}$ resistivity) were used in all the experiments. Potassium indigo trisulfonate, $\mathrm{C}_{16} \mathrm{H}_{7} \mathrm{~N}_{2} \mathrm{O}_{11} \mathrm{~S}_{3} \mathrm{~K}_{3}$ (at100\% purity) was purchased from ACROS Co. Other chemicals used in this study were reagent grade and supplied by MERCK.

The concentration of Methyltert-butyl ether and the sum of oxidation intermediates were determined by using a gas chromatograph equipped with flameionization detector (GC-FID, PU4410-PHILIPS) and with a SE30 column. Residual ozone concentration in the chemical reactor and ozone average concentration in off-gas (with $2 \%$ errors in sampling) were measured by Indigo Colorimetric and Iodometric Methods, respectively ( Standard methods, sections $4500-\mathrm{O}_{3} \mathrm{~B}$ and 4500-cl B.) [25]. For pH measurements an Orion $\mathrm{pH}$ electrode $\mathrm{pH} / \mathrm{T}^{\circ} \mathrm{C}$ model $520 \mathrm{~A}$ was used. $\mathrm{pH}$ prob was checked for true readings before any the run of the test. $\mathrm{BOD}_{5}$ was measured according to the procedures stipulated in Standard Methods [25] section 5210 B and to this subject, Inoculums was taken from the refinery wastewater plant in Esfahan (Iran). Chemical oxygen demand (COD) was also followed according to Dichromate Reactor Digestion (Hach Method 8000) by reagents for low COD.

A $3 \mathrm{~L}$ pilot-scale plant, made of glas, has been used in batch operation with MTBE and continuous with ozone (Fig.1). Liquid recirculates through a peristaltic pump at a flow rate of $9 \mathrm{~L} \mathrm{~h}^{-1}$. Ozone gas with a fixed rate of $400 \mathrm{mg} \mathrm{h}^{-1}$ at $1 \mathrm{~L} \mathrm{~h}^{-1} \mathrm{O}_{2}$ flow was bubbled into the reactor near the bottom through a glass dispersion tube (PYREX glass). Gas-liquid contact was ensured with a venture-type injector together with a special design for the hydraulic mixer that helps contact and mass transfer of ozone from gas phase to aqueous phase. The reactor was charged with a $100 \mathrm{mg} \mathrm{L}^{-1}\left(1.13 \mathrm{mmol} \mathrm{L}{ }^{-1}\right) \mathrm{MTBE}$ aqueous solution. The $\mathrm{pH}$ of the reaction solution was adjusted to 11.5 [25].

All experiments were performed at temperature $24 \pm 0.5^{\circ} \mathrm{c}$. samples were periodically (at $10 \mathrm{~min}$ intervals over $120 \mathrm{~min}$ run time) withdrown for $\mathrm{pH}$, GC-FID, COD, BOD 5 and residual ozone analysis. For determining of ozone concentration in the off-gas, the exit gas from reactor was passed through tow washing bottles filled with $200 \mathrm{ml}$ of $2 \%$ potassium iodide solution each $10 \mathrm{~min}$. In ozonation runs, the residual aqueous ozone was quenched with $1 \mathrm{~N} \mathrm{Na}_{2} \mathrm{~S}_{2} \mathrm{O}_{3}$.

\section{RESULTS AND DISCUSSION}

The transformation of MTBE and the variation of COD and $\mathrm{BOD}_{5}$ during ozonation are shown in Fig. 2. The results showed that as proceeding of MTBE transformation $\mathrm{COD}$ decreased and $\mathrm{BOD}_{5}$ initially increased and then decreased. The maximum value of $\mathrm{BOD}_{5}$ was $65.7 \mathrm{mg} \mathrm{L}^{-1}$ that occurred at $90 \mathrm{~min}$ from reaction start. The results also show significant decreases of COD within $60 \mathrm{~min}$ of ozonation. COD reduction after completely degradation of MTBE indicates that after MTBE degradation, ozone continues to react presumably by further oxidizing some "primary" MTBE degradation by-products. The figure also shows significant decreases of COD within $60 \mathrm{~min}$ of ozonation.

Figure 3 shows the variation of MTBE concentration and $\mathrm{pH}$ during ozonation. The results shows that with the addition of ozone to the reaction mixture, the rate of degradation was enhanced and $\mathrm{pH}$ value was decreased more than one unit during the experiment. Of course, such a $\mathrm{pH}$ trend indicates the formation of acid byproducts.

MTBE decay curve reported shows that its degradation is completely over within 100 minutes. Nevertheless, COD reduction (Fig. 2) partially go on.

Figure 4 shows the sum intermediates produced due to MTBE degradation and ozone concentration in aqueous 


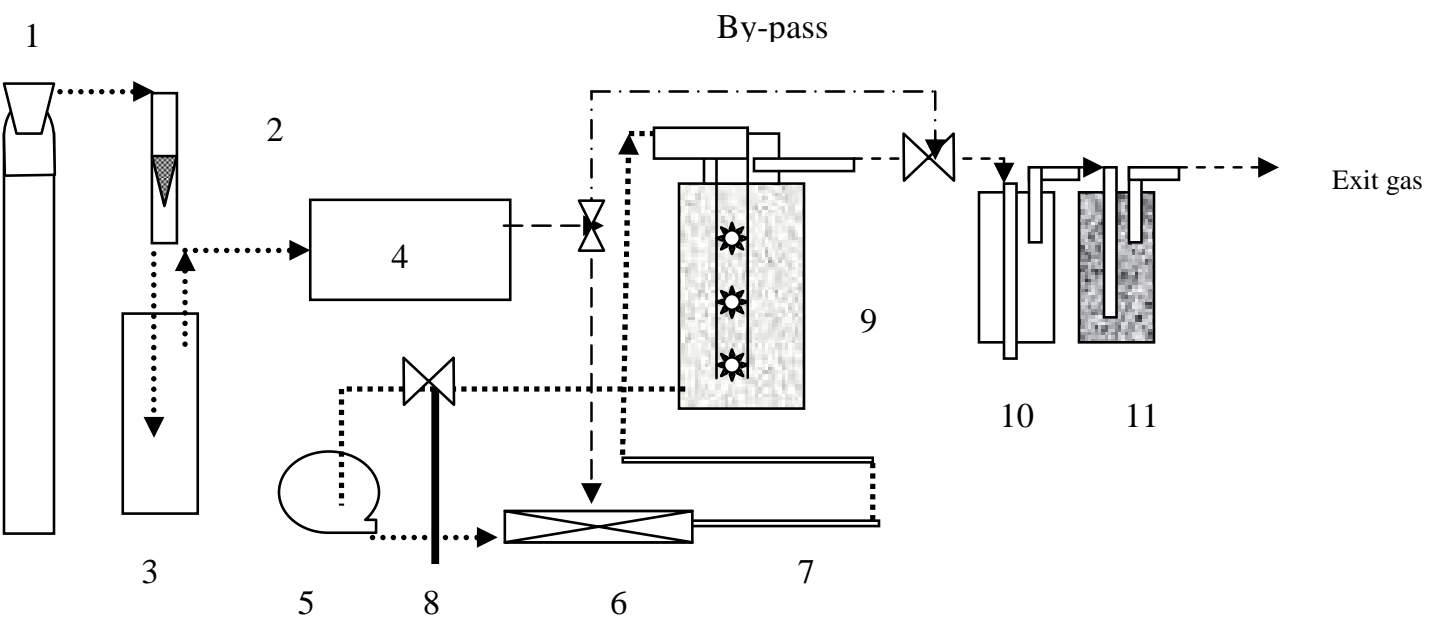

Fig. 1: Pilot Schematic: 1, Oxygen Cylinder; 2, Air Flow Meter; 3, Silica gel; 4, Ozone Generator; 5, Peristaltic Pump; 6, Venture-type Injector; 7, Blender; 8, Sampling Port; 9, Chemical Reactor; 10, Off-gas Ozone Collector; 11, Caryolit Column

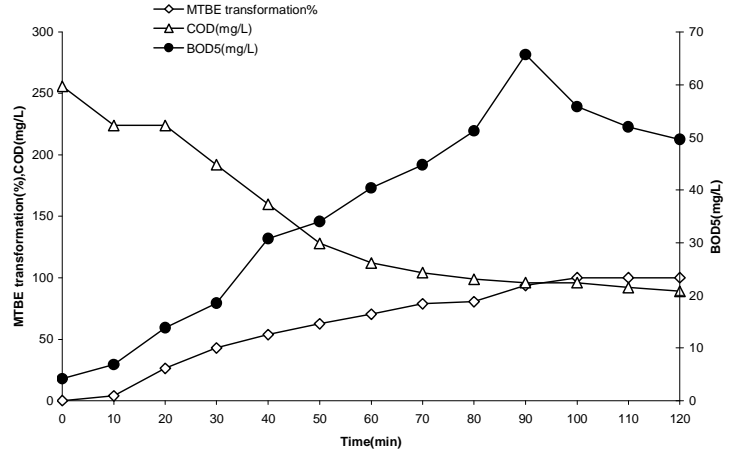

Fig. 2: Evolution of $\mathrm{COD}$ and $\mathrm{BOD}_{5}$ with $\mathrm{MTBE}$ Transformation During Ozonation

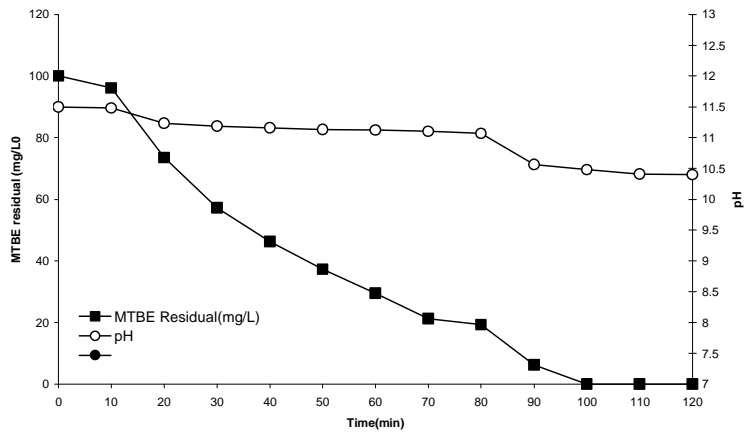

Fig. 3: Variation of MTBE, $\mathrm{pH}$ in Aquaous Mixture with a Time of Ozonation

mixture and off-gas from reactor with ozonation time. The total ozone amount out of the reactor has been calculated by integrating the profile in Fig. 4 resulting in $44.86 \mathrm{mg} \mathrm{O}_{3}$. Accordingly, TE (transfer efficiency) and the transferred dose result in $44 \%$ and $100.4 \mathrm{mg}$ $\mathrm{L}^{-1}$, respectively.

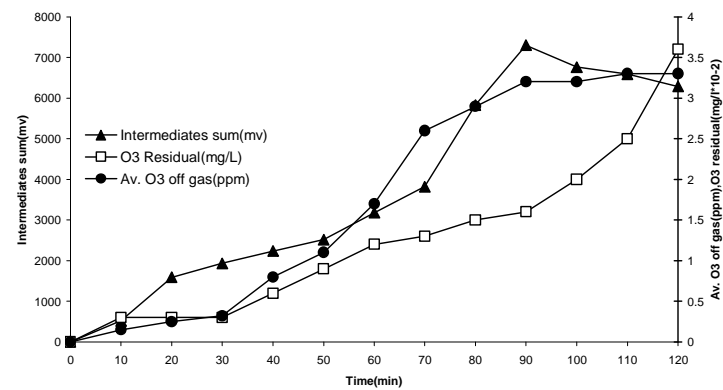

Fig. 4: Variation of Intermediates, Residual Ozone and $\mathrm{O}_{3}$ Off-gas from Reactor versus the Ozonation Time

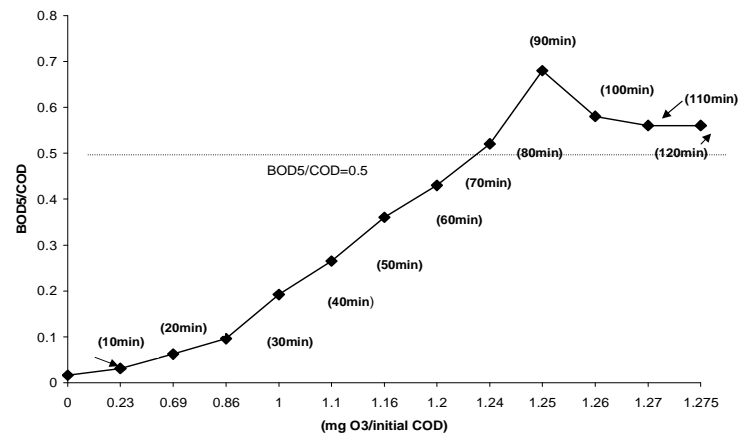

Fig. 5: Changes in Biodegradability (as measured by $\mathrm{BOD}_{5} / \mathrm{COD}$ ratios) of Intermediates resulting from Ozonation of MTBE at Different Times

Biodegradability of intermediates formed throughout ozonation was measured by $\mathrm{BOD}_{5}$ in comparison to COD in aliquots withdrawn periodically. Figure 5 shows the respective measurements along with the $\mathrm{BOD}_{5}$ to COD. From the technological stand point, assuming the ratio $\left(\mathrm{BOD}_{5}\right) /(\mathrm{COD})$ as indicative of solution biodegradability and looking at Fig. 5 where 


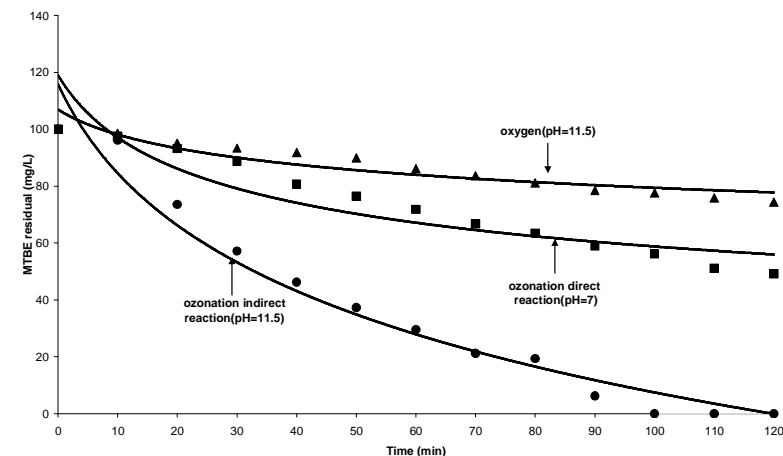

Fig. 6: Decay Time Profile of MTBE in Aqueous Mixture by Stripping and Ozonation. $\mathrm{O}_{3}$ in the Gas $\mathrm{Phase}=0.5 \mathrm{mg} \mathrm{L}^{-1}, \mathrm{pH}=7$ (direct reaction of $\mathrm{O}_{3}$ ), $\mathrm{pH}=11.5$ (indirect reaction of $\mathrm{O}_{3}$ )

such a ratio is reported versus the amount of ozone consumed per mg of initial chemical oxygen demand (COD。) during the ozonation, it results that the maximum biodegradability enhancement $\left[\mathrm{BOD}_{5} / \mathrm{COD}=0.68\right]$ is achieved after 90min of ozonation. As Fig. 5 shows the biodegradability indicator in ozonation primary stage increased slowly, due to primary by-products production, as ozonation progressed, this parameter increased faster, due to secondary by-products production.

Initial $\mathrm{BOD}_{5}$ values for MTBE without ozonation were lowest $\left(4 \mathrm{mg} \mathrm{L}^{-1}\right)$ reflecting the recalcitrant nature of MTBE with respect to biodegradation; however, as ozonation progressed $\mathrm{BOD}_{5}$ increased with ozonation time indicating that intermediates of the ozonated solutions were more biodegradable. The increasing ratios of $\mathrm{BOD}_{5}$ to $\mathrm{COD}$ indicated an increasingly more biodegradable nature of the ozonated solutions.

For biodegradable wastewater, $\mathrm{BOD}_{5}$ typically accounts for about $60-70 \%$ of the ultimated $\mathrm{BOD}\left(\mathrm{BOD}_{\mathrm{u}}\right)$; the latter would more closely approximate the COD for easily degraded wastes. Thus, at $70 \mathrm{~min}$ of ozonation time, the $\mathrm{BOD}_{5}$-to-COD ratio of 0.68 suggested the treated solution was very favorable for biodegradation.

Experiments were carried out to examine the effect of sparging and ozonation on the rate of removal MTBE from aqueous mixture. The results shown in Fig. 6 showed that about $14 \%$ of MTBE strips out after an hour of sparging with oxygen gas. The fraction of MTBE oxidized and/or striped increases to about $28 \%$ and $70 \%$ with ozonation by direct and indirect reactions, respectively over the same time period. On the other hand the concentration of MTBE is reduced by about 2 orders of magnitude after $40 \mathrm{~min}$ of ozonation in the presence of hydroxide ions. Consequently, it is dominated by reaction with hydroxyl radicals. Safarzadeh et al (2000) have reported that $10 \%$ and $30 \%$ of MTBE remove from aqueous mixture after an hour with oxygen gas and ozonation (in neutral $\mathrm{pH}$ ), respectively.

\section{CONCLUSION}

The conclusions of this study are:

* An ozonation time of $60-70 \mathrm{~min}$ is needed to biodegradability enhancement of MTBE and afterwards intermediates are amenable to biological degradation.

* While ozonation is capable of complete degradation of the recalcitrant given sufficient time (Other studies), a combination of an chemical oxidation followed by a wellestablished biological unit processes (a sequential chemical-biological treatment scheme) may be both technically and economically advantageous.

\section{ACKNOWLEDGEMENT}

The authors would like to express their thank and appreciation for Professor J. Nouri, the Iranian AJES Editor, for his great help and assistance during the submission of this paper.

\section{REFERENCES}

1. Michael, H., 1999. Final Report: Aerobic cometabolism of ether-bonded compounds. Banner for US EPA, National Center for Environmental Research (NCER).

2. Junzo, S., H. Keiko and S. Shizuo, 1978. Effect of ozone treatment upon biodegradability of watersoluble polymers. Environ. Sci. Technol., pp: 1180-84.

3. Ali, S.A., 2001. $\mathrm{O}_{3} / \mathrm{H}_{2} \mathrm{O}_{2}$ treatment of Methy-tertButyl Ether (MTBE) in contaminated water. Water Research, 35: 3706-14.

4. Clinton, D.C., M.I. Lorne, F.P. James, L.R. Donna and G.T. Paul, 1997. Method for determination of methyl tert-butyl ether and its degradation products in Water. Environ. Sci. Technol., 31: 3723-26.

5. Christine, A., K. Axel and P. Wilhelm, 2002. Methyl tert-Butyl Ether (MTBE) in river and wastewater in Germany. Environ. Sci. Technol., 36: 3652-61.

6. Boughton, C.J. and M.S. Lico, 1998. Volatile organic compounds in Lake Tahoe, Nevada and California, Fact Sheet FS-055-98, US Geological Survey.

7. Delzer, G.C., J.S. Zogorski, T.J. Lopes and R.L. Bosshart, 1996. Occurrence of the gasoline oxygenate MTBE and BTEX compounds in urban storm water in the United States. Water Resources Investigation Report 96-4145, US Geological Survey.

8. Clawges, R., J. Zogorski and D. Bender, 2000. Key MTBE findings based on National Water Quality Monitoring; US Geological Survey, http://wwwsd.cr.usgs.gov/naqua/vocns/. 
9. Contreras, S., M. Rodriguez, F. Almomani, C. Sans and S. Esplugas, 2003. Contribution of the ozonation pre-treatment to the biodegradation of aqueous 2,4-dichlorophenol. Water Research, 37: 3164-71.

10. Adams, C.D., R.A. Cozzens and B.J. Kim, 1997. Effects of ozonation on the biodegradability of substituted phenols. Water Research, 31: 2655-63.

11. Hui-Ming, H., K. Joon-Wun and R.H. Michael, 2002. The sonolytic destruction of methyl tertbutyl ether present in contaminated groundwater. Water Environment Research, 74: 6.

12. Chamarro, E., A. Marco and S. Esplugas, 2001. Use of Fenton reagent to improve organic chemical biodegradability. Water Research, 35: 1047-51.

13. Gilbert, E., 1987. Biodegradability of ozonation products as a function of COD and DOC elimination by example of substituted aromatic substances. Water Research, 21: 1273-78.

14. Marco, A., S. Esplugas and G. Saum, 1997. How and why to combine chemical and biological processes for wastewater treatment. Water Sci. Technol., 35: 321-327.

15. Langlais, B., D.A. Reckhow and D.R. Brink, 1991. Ozone in water treatment: Application and engineering. Chelsea: Lewis Publishers.

16. Scott, J.P. and D.F. Oills, 1995. Integration of chemical and biological oxidation processes for water treatment: Review and recommendations. Environmental Progress, 14: 88-103.

17. Beltran, F.J., J.M. Encinar and M.A. Alonso, 1998. Nitroaromatic hydrocarbon ozonation in water 1 single ozonation. Ind. Eng. Chem. Res., 37: 25-31.

18. Contreras, S., M. Rodriguez, E. Chamarro, S. Esplugas and J. Casado, 2001. Oxidation of nitrobenzene by $\mathrm{O}_{3} / \mathrm{UV}$ : The influence of $\mathrm{H}_{2} \mathrm{O}_{2}$ and $\mathrm{Fe}(\mathrm{III})$ experiences in a pilot plant. Water Sci. Technol., 44: 39-46.
19. Beltran, F.J., J.F. Garcia-Araya and P.M. Alvarez, 2000. Continuous flow integrated chemical (ozone)-activated sludge system treating combined agroindustrial-domestic wastewater. Environmental Progress, 19: 28-35.

20. Beltran, F.J., J.F. Garcia-Araya, J. Frades, P. Alvares and O. Gimeno, 1999. Effects of single and combined ozonation with hydrogen prroxide or UV radiation on the chemical degradation and biodegradability of debittering table olive industrial wastewater. Water Research, 33: 723-32.

21. Ledakowiez, S., 1998. Integrated processes of chemical and biological oxidation of wastewaters. Environmental Protect Engineering, 24: 35-47.

22. Adams, C.D., S. Spitzer and R.M. Cowan, 1996. Biodegradation of nonionic surfactants and effects of oxidative pretreatment. J. Environ. Eng., 122: 477-83.

23. Sarria, V., S. Parra, M. Invernizzi, P. Peringer and C. Pulgarin, 2001. Photochemical-biological treatment of a real industrial biorecalcitrant wastewater containing 5-amino-6-methyl-2benzimidazolone. Water Sci. Technol., 44: 93-103.

24. Mehraban, S., M. Ali Reza, B. Ahmad, N. Ramin, and S. Ardallan. Efficiency of advance oxydation and hydrocil technology in Methyl tertiary-Butyl Ether (MTBE). J. Shahr-E-Kord Medical Sci. (In Press).

25. Greenberg, A.E., L.S. Clesceri and A.D. Eaton, 1992. Standard Methods for Examination of Water and Wastewater. $18^{\text {th }}$ Edn. American Public Health Association, USA: 2.41-5.10. 